\title{
Optimization of Spot Welding Parameters in Similar and Dissimilar Alloys AISI-321 and Inconel-X750 Alloys
}

\author{
MUHAMMAD Mudassar Rauf* ${ }^{*}$, AAMIR Nusair Khan ${ }^{\mathrm{b}}$, IFTIKHAR Us Salam, \\ REHAN Qayyume ${ }^{d}$ and SHAHEED Khan ${ }^{\mathrm{e}}$
}

\author{
Institute of Industrial and Control System, Rawalpindi, Pakistan \\ aMudassar.79@hotmail.com, bnussair@yahoo.com, ciftikhar.salam@gmail.com, \\ drehan1606@gmail.com, epe_shaheed@hotmail.com
}

Keywords: Inconel-X750, Dissimilar alloys welding, Spot welding, welding parameters

\begin{abstract}
A series of experiments were conducted to optimize the welding of similar and dissimilar alloys i.e., AISI-321 with AISI-321, Inconel-X750 with AISI-321 and Inconel-X750 with InconelX750. Single phase rectification type resistance spot welding machine was utilized for this purpose. Breaking load against different welding parameters was observed. Further, the defects of the weld zone were also studied by optical and stereo microscopes. It was noted that the welding current, welding time and the welding force played an effective role in the strength of the weld joints and the spot welding of Inconel-X750 with AISI-321 can be possible if the welding parameters were carefully selected.
\end{abstract}

\section{Introduction}

Resistance spot welding is the most widely used joining technique for the assembly of sheet metal products such as, building products, vehicle assembly and to a limited extent, aircraft components [1-3]. Spot welding is a process in which faying surfaces are joined in one or more spots by the heat generated by resistance to the flow of electric current through work pieces that are held together under force by electrodes. The contacting surfaces in the region of current concentration are heated by a short-time pulse of low-voltage, high-amperage current to form a fused nugget of weld metal. When the flow of current ceases, the electrode force is maintained while the weld metal rapidly cools and solidifies. The electrodes are retracted after each weld, which usually is completed in a fraction of a second [4, 5]. Major advantages of spot welding include high operating speeds and suitability for automation in high-production assembly lines together with other fabricating operations [6] With automatic control of current, timing, and electrode force, sound spot welds can be produced consistently at high production rates and low unit labor costs using semiskilled operators [7].

There are number of applications where it is necessary to design components made of different materials. In general these applications take advantage of combination of dissimilar materials and provide engineering advantages. In this regard, nickel base superalloys have an advantage of retaining high temperature strength and oxidation resistant properties $[8,9]$, therefore, it can be utilized in combination with other metals. In this paper the welding parameters are tried to optimize for dissimilar metals i.e. AISI-321 and Inconel X750.

\section{Experimental}

The material used in the experiments was $1.8 \mathrm{~mm}$ thick Inconel X-750 and $1.5 \mathrm{~mm}$ thick AISI321 sheets. The chemical composition of both materials was measured by using Energy Dispersive Spectrometer and the results are presented in Table 1. Before, spot welding the sheets were cut in the dimension of $70 \times 10 \mathrm{~mm}$ and thoroughly cleaned to remove any contamination. For spot welding a single phase rectification type resistance spot welding machine was utilized. In-order to optimize the welding parameters a series of experiments were conducted. The details of the experiments are given in Table 2. 
Table 1. Chemical composition of the Sheets used in experiments

\begin{tabular}{|c|c|c|}
\hline \multirow{2}{*}{ Elements } & \multicolumn{2}{|c|}{ Alloys } \\
\cline { 2 - 3 } & AISI-321 & Inconel-X750 \\
\hline Fe & Balance & 7.3 \\
\hline $\mathbf{C r}$ & 18.01 & 15.41 \\
\hline $\mathbf{N i}$ & 9.7 & Balance \\
\hline $\mathbf{M n}$ & 0.75 & 0.39 \\
\hline $\mathbf{T i}$ & 0.49 & 2.47 \\
\hline $\mathbf{S i}$ & 0.43 & 0.45 \\
\hline $\mathbf{C}$ & 0.07 & 0.032 \\
\hline $\mathbf{S}$ & 0.0047 & 0.0022 \\
\hline $\mathbf{N b}$ & - & 0.74 \\
\hline $\mathbf{A l}$ & - & 0.62 \\
\hline
\end{tabular}

Table 2. Details of the experimentation and the nomenclature used in the manuscript

\begin{tabular}{|c|r|c|c|}
\hline Nomenclature & Spot welding of sheets & $\begin{array}{c}\text { Weld Time, } \\
\text { Cycles }\end{array}$ & Force, Bar \\
\cline { 1 - 2 } Set-1 & AISI-321 with AISI-321 & 3 & 3 \\
\cline { 1 - 2 } Set-2 & AISI-321 with Inconel-X750 & & \\
\cline { 1 - 2 } Set-3 & Inconel-X750 with Inconel-X750 & & \multirow{2}{*}{3} \\
\cline { 1 - 2 } Set-4 & AISI-321 with AISI-321 & \\
\cline { 1 - 2 } Set-5 & AISI-321 with Inconel-X750 & & \\
\cline { 1 - 2 } Set-6 & Inconel-X750 with Inconel-X750 & & \\
\cline { 1 - 2 } Set-7 & AISI-321 with AISI-321 & & \\
\cline { 1 - 2 } Set-8 & AISI-321 with Inconel-X750 & & \\
\cline { 1 - 2 } Set-9 & Inconel-X750 with Inconel-X750 & & \\
\hline
\end{tabular}

After spot welding different tests were conducted on the specimen (Fig. 1). In these tests, tensile testing was performed at cross-head speed of $1 \mathrm{~mm} /$ minute on universal testing machine. For this purpose at least three specimens were tested at ambient temperature. For metallographic observations, in which the welding defects and the welding nugget included, an optical and stereo microscopes were utilized.

\section{Results and Discussion}

Mechanical Testing of As-Received Sheets. Before performing shear tension strength tests on the welded joints the mechanical properties of the as-received sheet of AISI-321 and Inconel-X750 were determined. The results of the as-received sheets are given in Table 3. 


\section{$140 \mathrm{~mm}$}

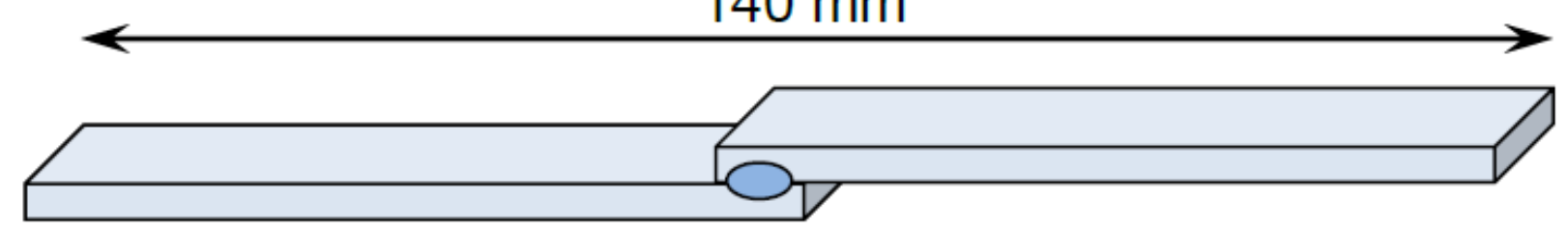

Fig. 1. Specimen of shear tension test after spot welding

Table 3. Mechanical properties of as-received sheets

\begin{tabular}{|l|c|c|}
\hline \multirow{2}{*}{ Property } & \multicolumn{2}{|c|}{ Alloy } \\
\cline { 2 - 3 } & AISI-321 & Inconel-X750 \\
\hline Tensile, MPa & 515 & 910 \\
\hline Yield, MPa & 205 & 470 \\
\hline Elongation, \%age & 40 & 36 \\
\hline
\end{tabular}

\section{Mechanical Testing of Spot Welded Sheets.}

Spot Welding of AISI-321 with AISI-321 (Set-1, Set-4 and Set-7). The spot welding of AISI321 with AISI-321 (Set-1 and Set-4) demonstrates that breaking load increases with increase in welding current up to $15 \mathrm{KA}$, Fig .2. Beyond this welding current the breaking strength of the weld became constant and then started to decrease. This is due to the fact that the heat generation is directly proportional to the square of the welding current. Thus the high welding current may cause expulsion and weakening the welding strength. Further, it was revealed that there is no apparent effect of the welding force since both at 3 bar and 4 bar the breaking strength was almost similar. However, when the available data was plotted against the different welding force at constant welding current $15.3 \mathrm{KA}$, this was the welding current where maximum breaking strength was achieved (Fig. 2a), a linear increase in breaking strength was achieved, Fig. 2b.
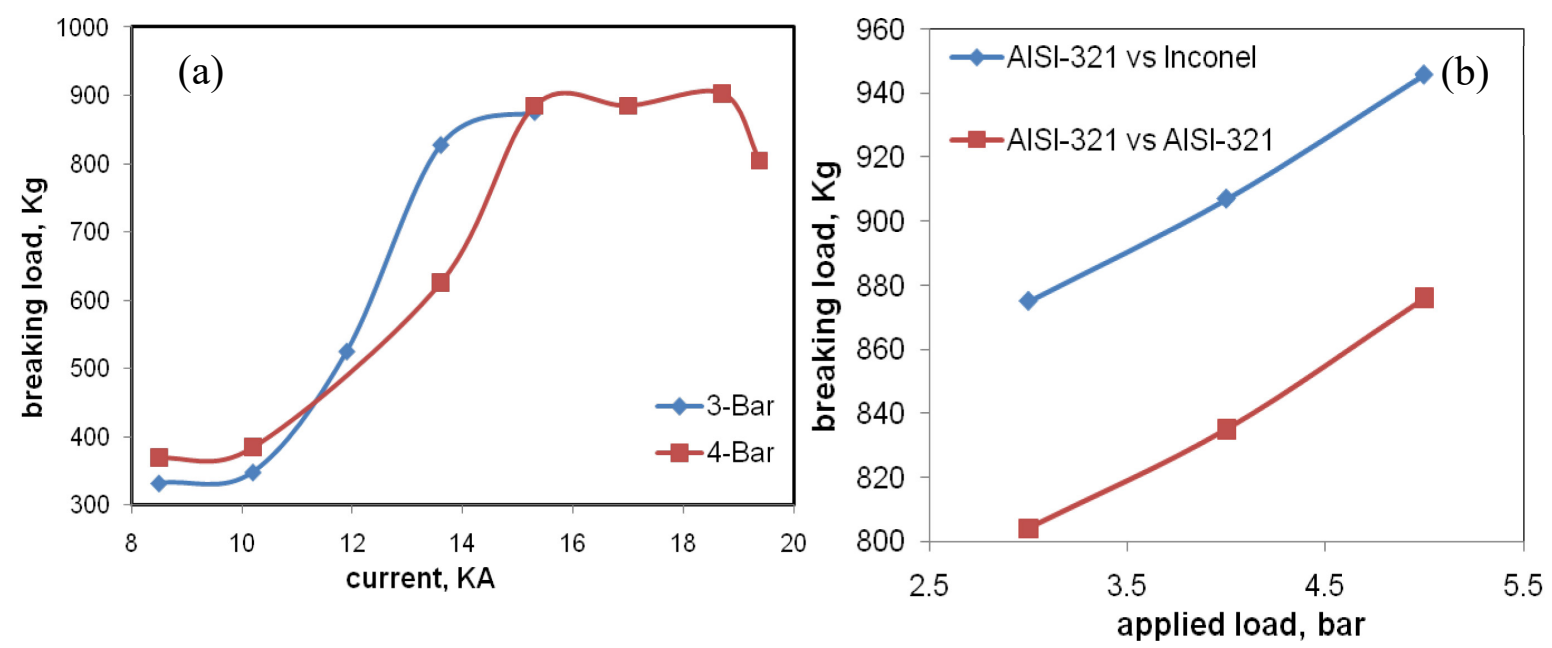

Fig. 2. (a) Breaking load, for Set-1, against the welding current. (b) Breaking load against applied force during spot welding at constant current $15.3 \mathrm{KA}$

It was revealed that at 5 bar welding force, the maximum breaking strength for AIS321 vs AISI321 (Set-4) was about $870 \mathrm{Kg}$. Thus 5 bar of welding force was selected as an optimum welding force for these experiments, beyond this force there was a chance of damage of weldingmachine's electrodes; therefore, the force was not increased. After selecting the optimum welding force, it was decided to increase the welding time and once again the breaking strength of the welds was observed by varying the welding current. Thus set-7 was made. It was observed that the breaking load constantly increases with increase in welding current, Fig. 3. 


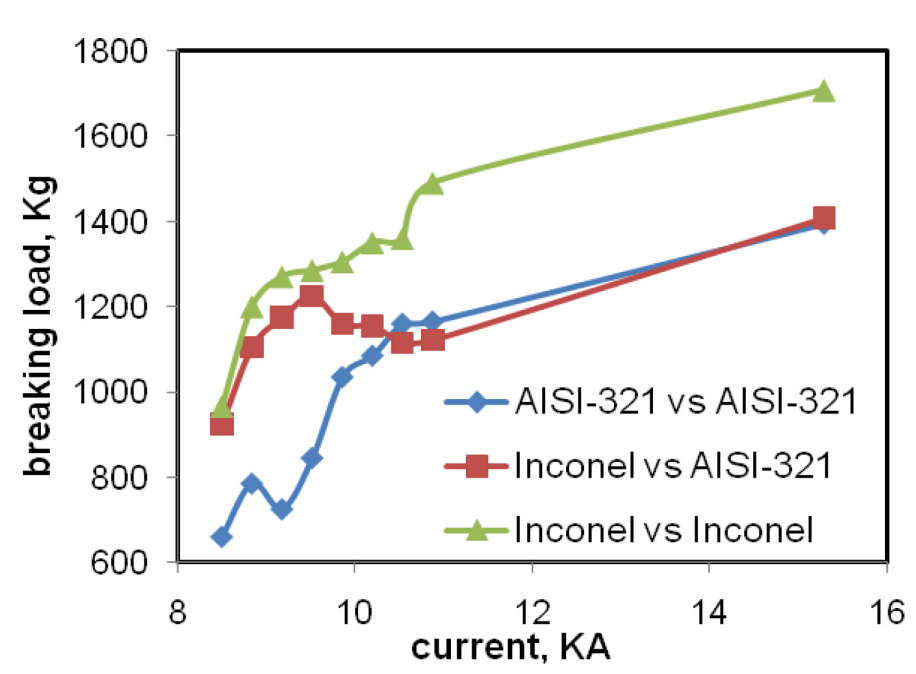

Fig. 3. Breaking load against applied current at welding time 15 cycles

Spot Welding of AISI-321 with Inconel-X750 (Set-2, Set-5 and Set-8). From the experience of stainless-steel with stainless-steel spot welding, the welding current 15.3 KA was selected and then effect of welding force was observed against the breaking load under tensile conditions, Fig.3. Similar results, as in stainless steel with stainless steel welding, were observed i.e. the breaking load increased with increased welding force, when welded for 15 cycles welding time,

Fig. 4. However, it can be noted that the maximum breaking load for AISI-321 with InconelX750 (set-8) was similar to that of stainless-steel with stainless steel (set-7) welding. Further, for set-2 \& 5, it was observed in Fig. 4, that the sustained breaking load increased by increasing the welding force, whereas, the optimum value of welding current was also changed by changing the welding force.

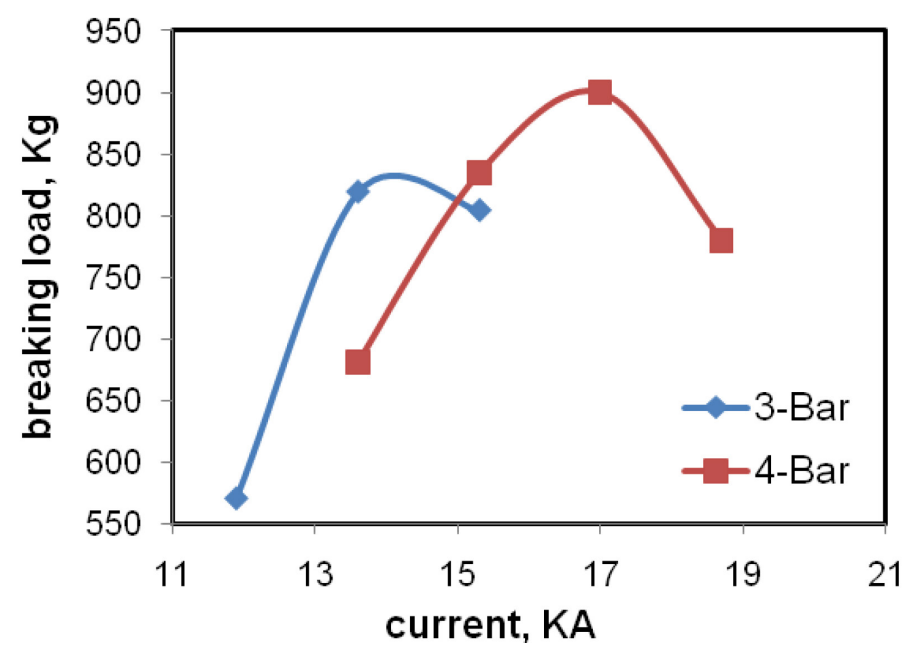

Fig. 4. Breaking load, for Set-2 \&5, against the welding current

It was noted that the maximum breaking load was achieved for $17 \mathrm{KA}$ welding current at welding force 4 bar. The welding force influenced the resistance of the metals, during the welding process by directly effecting on the contact resistance at the interface.

Spot welding of Inconel-X750 with Inconel-X750. In case of Inconel-Inconel (set-3) spot welding, when the welding time and the welding force was very small i.e. 3 cycles and 3 bar respectively then it was observed that the breaking load was increasing with increasing the welding current, Fig. 5a. However, for the same parameters in set-6, where the welding force was increased, it was revealed that by increasing the welding force, from 3 bar to 4 bar, the breaking load was relatively remained constant at higher welding current, Fig. 5a, which was may be due to the excessive splashing and expulsion of the base metals, Fig. $5 \mathrm{~b}$. 

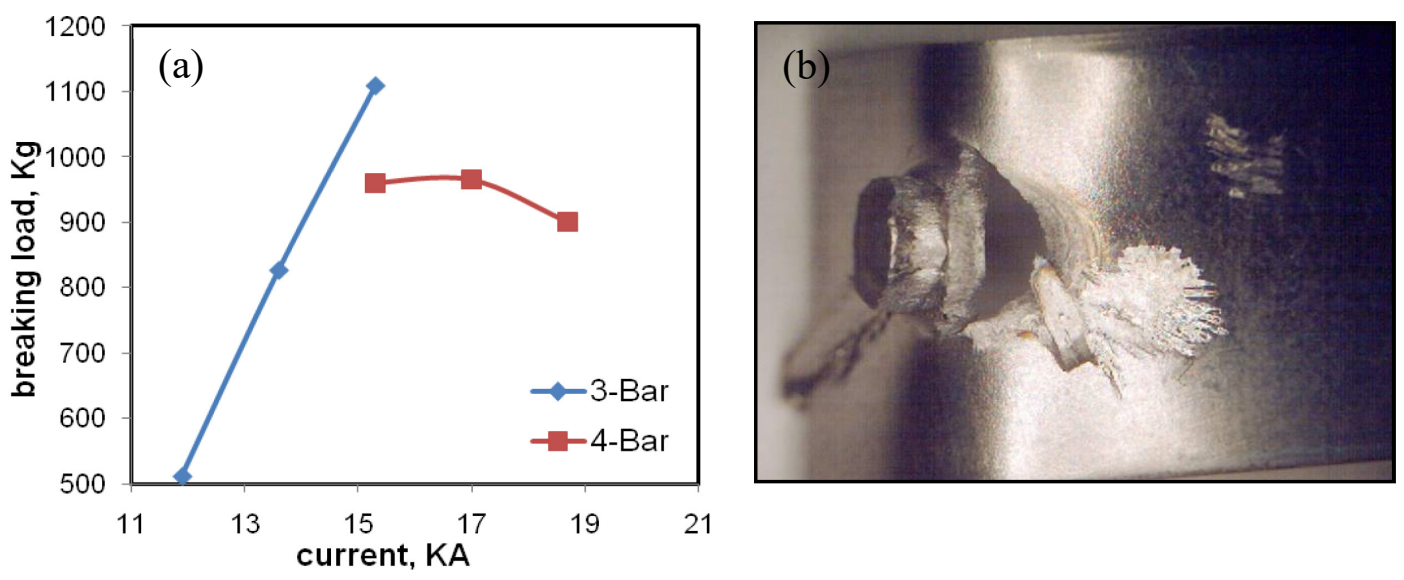

Fig. 5. (a) Breaking load, for Set-3 \& 6, against the welding current. (b) Inconel-Inconel sample after the tensile testing. The sample was welded at 17KA, 5 bar and 10 cycles

The excessive splashing reduced the strength of welding joint and may caused the failure outside the indented area [10-12]. Similarly, when the data of set-9 was plotted for welding current 15.3 KA, tit was the welding current where maximum breaking load was achieved in most sets of spot welding, and $17 \mathrm{KA}$ against the welding time it was observed that an increase in breaking load was achieved, Fig. 6a, but high welding current and welding time effected the welding nugget.
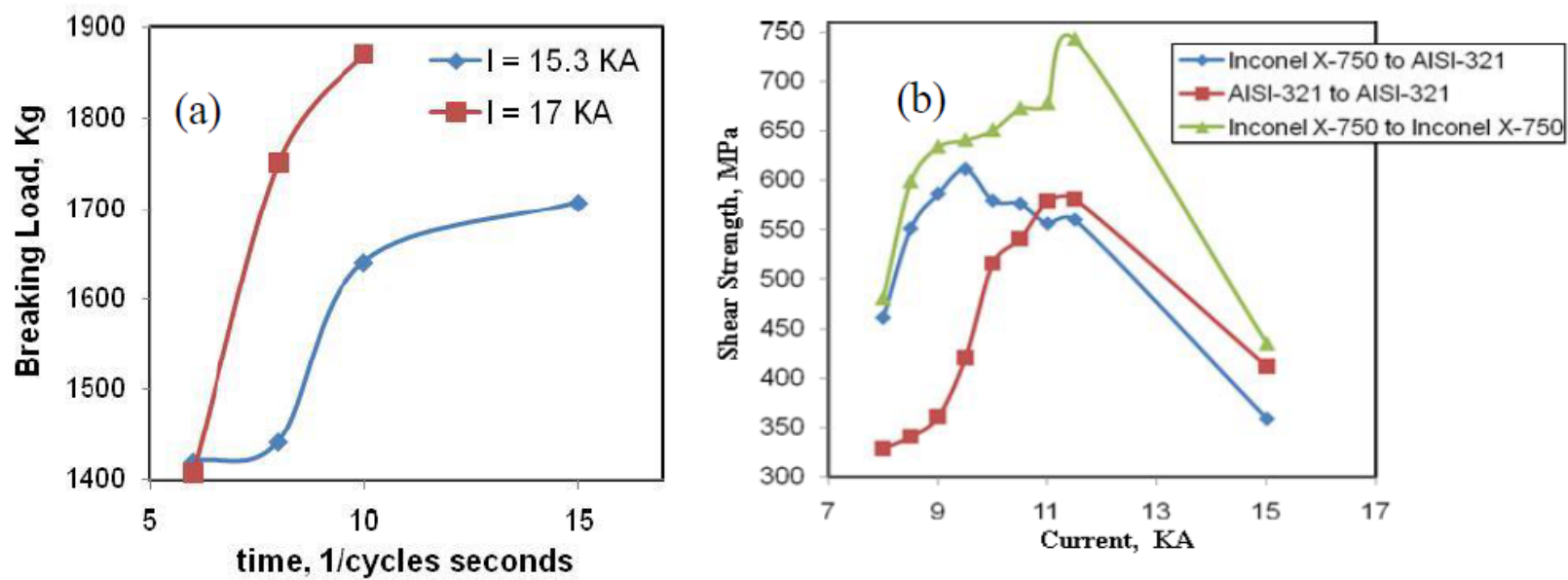

Fig. 6. (a) Breaking load, for Set-9, against the welding time for constant welding force i.e. 5 bar.

(b) Effect of welding current on the shear strength of different samples

After plotting the shear strength in set-7, 8 and 9, it was observed that, in case of similar metals welding i.e, either inconel to inconel or AISI-321 to AISI-321, the maximum shear strength was achieved at $11.5 \mathrm{KA}$ welding current, Fig. $6 \mathrm{~b}$. Whereas, the welding of dissimilar metals i.e. Inconel to stainless steel, demonstrated lower welding current where maximum shear strength was achieved. Beyond these currents, it was observed that the formation of nuggets became abnormal.

Microstructure Evaluation. Optical microscopy technique was utilized to examine the microstructure of the spot welded zone. In this regard, Set-7, 8 and 9 were selected because these were the set where the welding parameters were finally optimized. It can be clearly revealed from Fig. 7, that when the shear strength was maximum at welding-current 11.5KA (Fig. 6b), the spot welding-nuggets were in their ideal shape. In Fig.7 (Set-8) the center line of the weld pool is away from X750 and well within SS321. The thermal conductivity of SS-321 is comparatively higher than X750. The higher thermal conductivity is the most probable source of generating more heat in SS321 and therefore shifting the center line away from Inconel X750. 


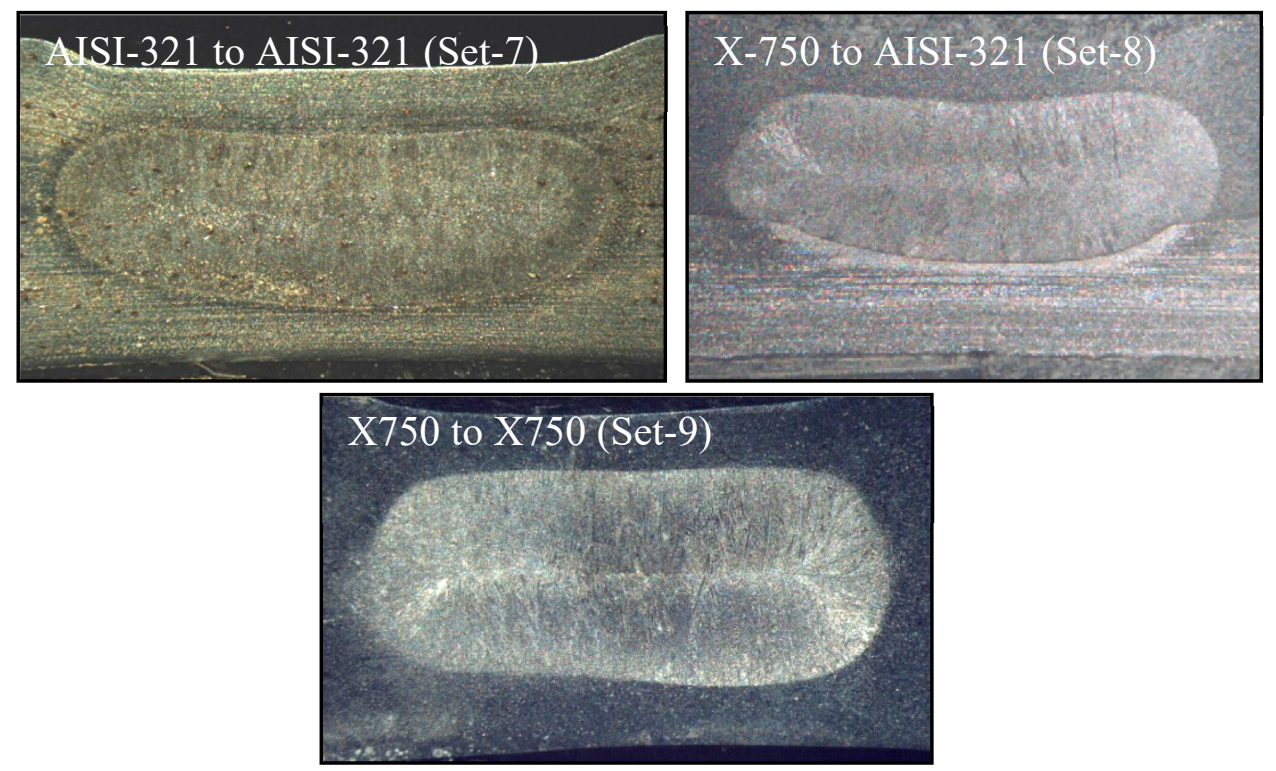

Fig.7. Ideal welding-nuggets formed for Set-7, $8 \& 9$ at welding current $11.5 \mathrm{KA}$

Similarly, it was observed that when the welding current was on the lower side i.e. lower than 11.5 KA, then the shape of welding-nugget was abnormally small, Fig. 8. Whereas, at higher welding currents, i.e. at 15.3KA, defects were observed in the welding-nuggets, Fig. 9.
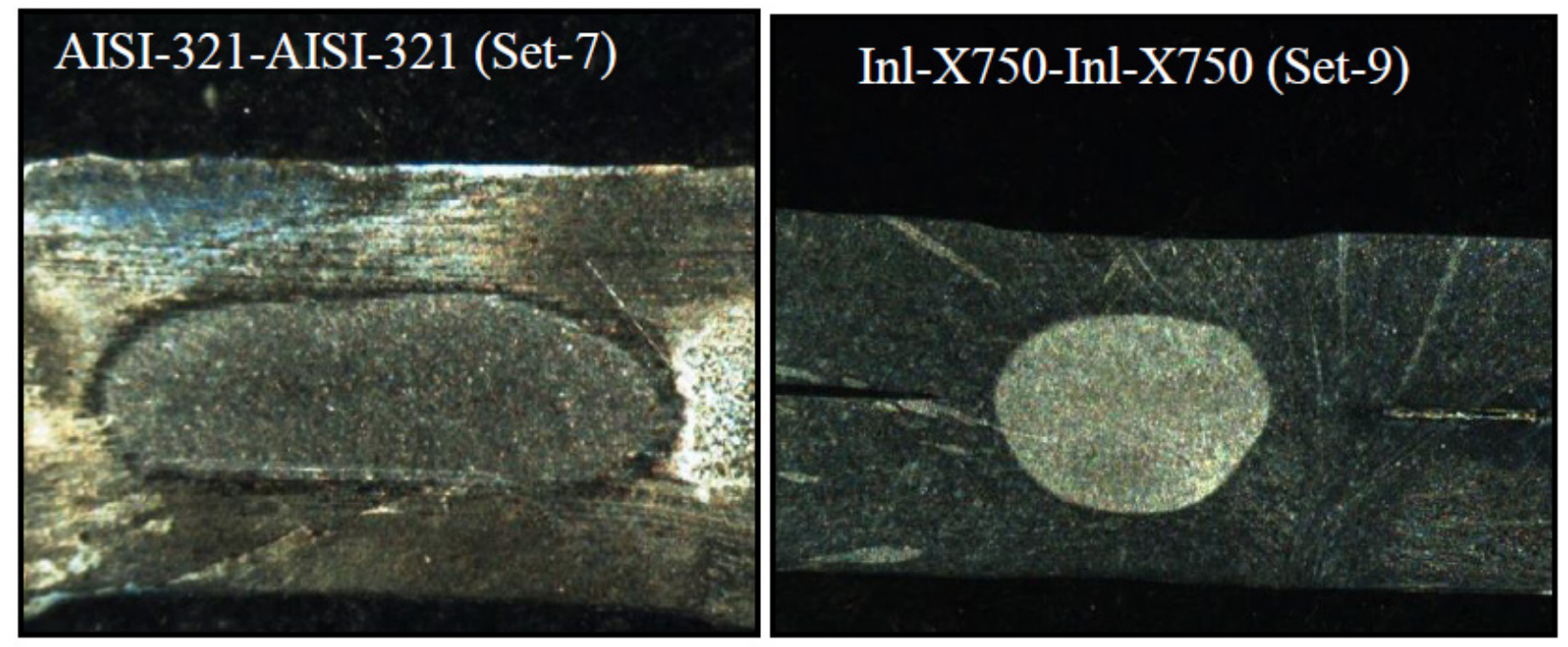

Fig. 8. Spot welding nuggets for Set-7 \& 9 at welding current $9.18 \mathrm{KA}$
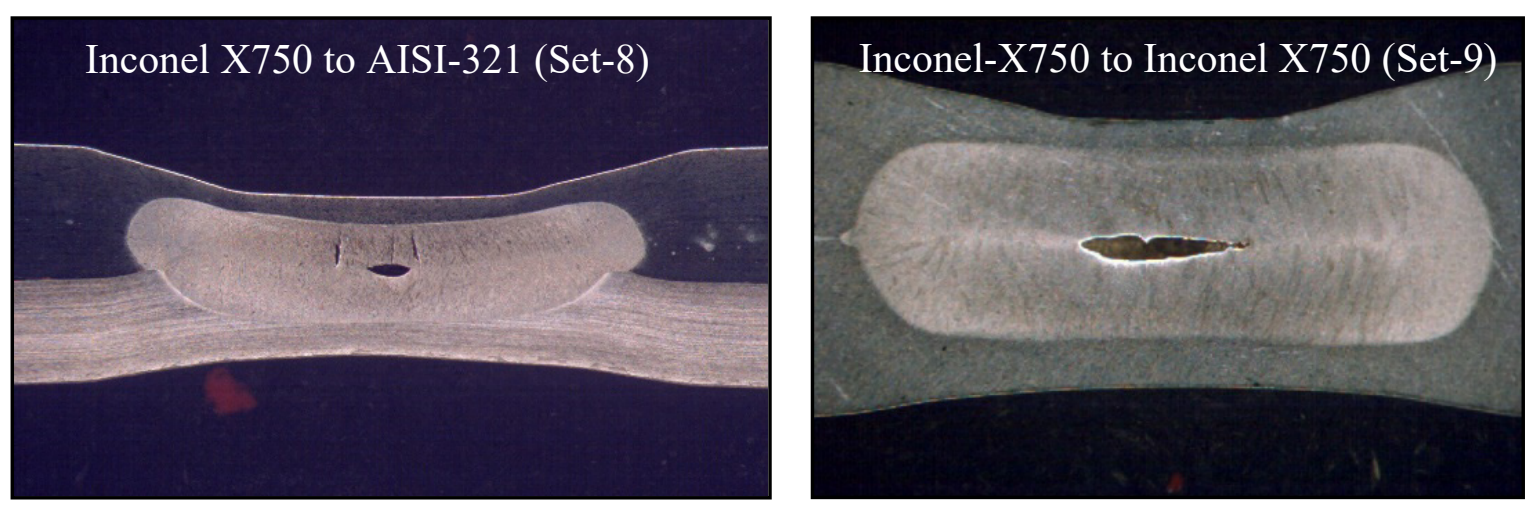

Fig. 9. Welding-nuggets formed in Set- $8 \& 9$ at welding current $15.3 \mathrm{KA}$, where defects are visible 


\section{Conclusions}

1. Different welding parameters were utilized to optimize the breaking strength of the AISI321 with AISI-321, AISI-321 with Inconel-X750 and Inconel-X750 with Inconel-X750.

2. It was observed that the shear strength is directly proportional to current up to the certain value and then decreases due to splashing of molten metal, which creates the shrinkage cavity and other defects.

3. The welding nugget became abnormally small at lower current and hence decreased the overall shear strength of the welding joint. The spot welding of Inconel-X750 with AISI-321 can be possible and effective if the welding parameters are carefully selected.

\section{References}

[1] S. Agashe, and H. Zhang, Selection of schedules based on heat balance in resistance spot welding. Weld. J. 82 (2003) 179-s-183-s.

[2] X. Sun, E.V. Stephens, R.W. Davies, M.A. Khaleel, and D.J. Spinella, Effects of fusion zone size on failure modes and static strength of aluminum resistance spot welds. Weld. J., 83 (2004) 308-s- 318-s.

[3] Y. Y. Zhao, Y. S. Zhang, and Pei-Chung Wang, Weld Formation Characteristics in Resistance Spot Welding of Ultra-Thin Steel. Weld. J., 96 (2017) 71s-82s.

[4] R.F. Nunes, B.L. Alia, R.L. Alley et al. Welding Brazing and Soldering, ASM Hand Book (soft version), ASM International, Materials Park, Ohio, volume-6 (1993) 684-672.

[5] P P Choughule, A K Biradar, A K Modi., Resistance Spot Weldability of Dissimilar Materials in 1 Mm Thick Sheet, J. Mech. Eng. Tech., 4 (2016) 15-21.

[6] Manoj Raut, Vishal Achwal., Optimization of Spot Welding Process Parameters for Maximum Tensile Strength, Int. J. Mech. Eng. Rob. Res., 3 (2014) 506-517.

[7] J. N. DuPont, J.C. Lippold, S. D. Kiser, Welding Metallurgy and Weldability of Ni base superalloys, John Wiley and Sons Inc, Hoboken, New Jersey, (2009).

[8] M.J. Donachie and S. Donachie, Superalloys a Technical Guide, $2^{\text {nd }}$ edition, ASM Inter. Materials Park, Ohio, (2002), 8.

[9] Alejandro Hinojos, Jorge Mireles, Ashley Reichardt, Pedro Frigola, Peter Hosemann, Lawrence E. Murr, Ryan B.Wicker., Joining of Inconel 718 and 316 Stainless Steel using electron beam melting additive manufacturing technology, Mater. Desin., 94 (2016) 17-27.

[10] S. Aslanlar, The effect of button size on mechanical properties in electrical resistance spot welding of sheets used in automotive industry. Mater. Desig., 27 (2006) 125-s - 131-s.

[11] M. Kimchi, Spot weld properties when welding with expulsion - A comparative study. Weld. J., 63 (1984) 58-s - 63-s.

[12] H. E. Emre And R. Kaçar., Resistance Spot Weldability of Deformed TRIP800 Steel, Weld. J., 95 (2016) 77s-85s. 